ANALYSIS OF THE RESULTS OF VEHICLES DAMAGES

ANALIZA WYNIKÓW BADAŃ USZKADZALNOŚCI POJAZDÓW SAMOCHODOWYCH

\author{
Grzegorz Feliczak \\ Państwowa Wyższa Szkoła Zawodowa w Lesznie \\ grzegorz.feliczak@wp.pl
}

\begin{abstract}
Summary: This article contains information about issues of vehicles damages (failure). Presents selected organization dealing with research in vehicles damages. For example, an analysis of selected results of research conducted and published by the selected organizations, including websites, showing similarities and differences. It also indicated the need for harmonization of research and the creation of a universal method for testing and analysis of this issue.
\end{abstract}

Keywords: vehicles, damages, ranking

Streszczenie: Artykul zawiera informacje dotyczace zagadnienia uszkadzalności (usterkowości) pojazdów samochodowych. Przedstawiono wybrane organizacje zajmujące się badaniem uszkadzalności pojazdów samochodowych. Na wybranym przyktadzie przeprowadzono analize wyników badań prowadzonych $i$ opublikowanych przez wybrane organizacje, między innymi na stronach internetowych, wykazując podobieństwa i różnice. Wskazano również na potrzebe ujednolicenia badań $i$ stworzenie jednej uniwersalnej metody badań $i$ analiz omawianego zagadnienia.

Słowa kluczowe: samochody, uszkadzalność, ranking 
Analysis of the results of vehicles damages

Analiza wyników badań uszkadzalności pojazdów samochodowych

\section{Uszkodzenie pojazdu samochodowego}

Ważnym aspektem w dobie gwałtownego rozwoju motoryzacji, jaki można zaobserwować, staje się zagadnienie uszkadzalności, potocznie nazywane usterkowością. Biorąc pod uwagę definicję nieuszkadzalności podanej w pracy [2] jako uszkadzalność można rozumieć własność obiektu, charakteryzującą jego tendencję do przejścia w stan niezdatności podczas wykonywania założonego zadania.

Uszkadzalność jest jak się wydaję jednym z wielu kryteriów, które jest brane pod uwagę przez potencjalnego klienta podczas zakupu danego modelu samochodu. $\mathrm{Na}$ całym świecie są organizacje prowadzące rankingi uszkadzalności. Ich wyniki publikowane są corocznie, stają się swoistą wyrocznią dla osoby, która zamierza nabyć pojazd. Prowadząc jednak ich analizę można zauważyć, że w zależności od organizacji przeprowadzającej ranking, rezultaty nieco się różnią od siebie. Tendencję taką można nawet zauważyć w ramach jednego modelu pojazdu. Jak widać, brakuje jednego spójnego modelu badań w tym zakresie.

\section{Badania uszkadzalności prowadzone przez wybrane organizacje}

Badania uszkadzalności pojazdów samochodowych przeprowadza się corocznie na całym świecie. Niestety w Polsce nie prowadzi się na szeroką skale analiz w tym zakresie. W związku z powyższym do analizy wybrano wyniki trzech niemieckich organizacji: TÜV, DEKRA i ADAC. Wybierając te organizację kierowano się miedzy innymi faktem, że rynek niemiecki jest jednym z najbardziej rozwiniętych rynków motoryzacyjnych $\mathrm{w}$ Europie, wyniki badań są kompatybilne oraz, że na terenie Niemiec zlokalizowanych jest wiele siedzib i przedstawicielstw światowych koncernów motoryzacyjnych.

\section{Badania prowadzone przez $T \ddot{U} V$}

Jedną $\mathrm{z}$ czołowych organizacji niemieckich prowadzących między innymi działalność w omawianym zakresie jest TÜV (z niem.: Technische Überwachung Verein - Stowarzyszenie Dozoru Technicznego). Rankingi uszkadzalności pojazdów samochodowych powstają na podstawie wyników badań, które zbierane są przy okazji obowiązkowych okresowych badań technicznych przeprowadzanych na terenie stacji kontroli pojazdów.

Organizacja ta wyniki swoich badań publikuje corocznie w postaci raportów, w których pojazdy dzieli na pięć kategorii wiekowych. Pierwsza grupa to samochody w wieku do 3 lat, druga - od 4 do 5 lat, trzecia - od 6 do 7 lat, czwarta - od 8 do 9 lat i piąta od 10 do 11 lat od daty produkcji. By dana marka pojazdu mogła trafić do raportu, musi zostać przebadanych co najmniej 500 egzemplarzy danego modelu w jednej grupie wiekowej. Wynik publikowany jest jako wartość procentowa istotnych uszkodzeń (usterek), jakie ujawniono wśród 100 przebadanych egzemplarzy danego modelu pojazdu.

Poniżej w tablicy 1 podano wybrane wyniki pierwszych i ostatnich dziesięciu miejsc dla pojazdów samochodowych opublikowane w roku 2003, dla grupy pojazdów do 3 lat. Pełny raport można znaleźć w [3]. 
Tablica 1

Raport uszkadzalności TÜV z 2003 r. - samochody do 3 lat [1,3]

\begin{tabular}{|c|l|c|}
\hline $\begin{array}{c}\text { Miejsce } \\
\text { w } \\
\text { raporcie }\end{array}$ & Marka/Model & $\begin{array}{c}\text { Uszkodzenia } \\
{[\%]}\end{array}$ \\
\hline 1 & 2 & 3 \\
\hline 1 & Toyota Yaris & 1,30 \\
\hline 2 & Mazda Demio & 2,10 \\
\hline 3 & Toyota Corolla & 2,20 \\
\hline 4 & Toyota Picnic & 2,20 \\
\hline 5 & Toyota Avensis & 2,30 \\
\hline 6 & Mercedes- Benz SLK & 2,50 \\
\hline 7 & Mazda MX-5 & 2,60 \\
\hline 8 & Subaru Legacy & 2,70 \\
\hline 9 & Toyota Starlet & 2,70 \\
\hline 10 & Porsche 911 & 2,80 \\
\hline & Średnia uszkodzeń & 2,34 \\
\hline 101 & Alfa Romeo 145/146 & 8,70 \\
\hline 102 & Suzuki Wagon R+ & 8,70 \\
\hline 103 & Nissan Serena & 8,90 \\
\hline 104 & Skoda Felicia & 8,90 \\
\hline 105 & Ford Galaxy & 9,00 \\
\hline 106 & Mitsubishi Galant & 9,40 \\
\hline 107 & Peugeot 806 & 10,40 \\
\hline 108 & Seat Alhambra & 10,60 \\
\hline 109 & VW Sharan & 11,10 \\
\hline 110 & Chrysler Voyager & 14,70 \\
\hline & Średnia uszkodzeń & 10,04 \\
\hline Średnia uszkodzeń dla samochodów do 3 lat & 5,20 \\
\hline
\end{tabular}

\section{Badania prowadzone przez DEKRA}

Organizacja DEKRA działa w podobnym zakresie co TÜV. Przeprowadza badania techniczne w stacjach kontroli pojazdów, prowadzi również działalność w zakresie rzeczoznawstwa samochodowego, jak również w swoim ośrodku badawczym w Neumünster przeprowadza badania zderzeniowe. To właśnie na podstawie danych zebranych z ww. obszarów publikuje corocznie swój raport uszkadzalności pojazdów.

W raportach dzieli DEKRA pojazdy na trzy grupy wiekowe: samochody do 3 lat, do 5 lat oraz samochody do 7 lat od daty produkcji. Dodatkowo z porównaniu z raportami TÜV, uzupełnia ona swoje raporty o szczegółowe zestawienie uszkodzeń dla konkretnych układów pojazdu samochodowego. Raporty publikowane w postaci tabel zawierają podział uszkodzeń (usterek) na trzy grupy: „brak uszkodzeń”, „nieznaczne uszkodzenia” i „poważne uszkodzenia”.

W tablicy 2 podano wyniki dla wybranej grupy pojazdów dla pierwszych dziesięciu miejsc publikowane w 2002 r. Pełen raport można znaleźć w [4]. 
Analysis of the results of vehicles damages

Analiza wyników badań uszkadzalności pojazdów samochodowych

Tablica 2

Raport uszkadzalności DEKRA z 2002 r. .- samochody 3-letnie [1,4]

\begin{tabular}{|c|c|c|c|c|}
\hline Lp. & Marka / model & $\begin{array}{c}\text { Brak } \\
\text { uszkodzeń } \\
\text { [\%] }\end{array}$ & $\begin{array}{c}\text { Nieznaczne } \\
\text { uszkodzenia } \\
{[\%]}\end{array}$ & $\begin{array}{c}\text { Poważne } \\
\text { uszkodzenia } \\
{[\%]}\end{array}$ \\
\hline & 1 & 2 & 3 & 4 \\
\hline \multicolumn{5}{|c|}{ Pierwsze dziesięć miejsc w rankingu } \\
\hline 1 & Mercedes - Benz klasy A & 95,1 & 3,7 & 1,2 \\
\hline 2 & VW Golf IV & 93,4 & 4,6 & 2,1 \\
\hline 3 & Porsche Boxster & 88,9 & 6,4 & 4,6 \\
\hline 4 & Mazda 323 & 88,7 & 7,9 & 3,4 \\
\hline 5 & Mercedes - Benz CLK & 88,6 & 7,9 & 3,5 \\
\hline 6 & Mazda 626 & 87,9 & 8,5 & 3,6 \\
\hline 7 & Jaguar XJ & 87,1 & 9,6 & 3,4 \\
\hline 8 & VW Golf Cabrio & 86,9 & 9,2 & 3,9 \\
\hline 9 & Porsche 911 & 86,4 & 9,6 & 4,0 \\
\hline 10 & BMW Z3 & 86,3 & 9,3 & 4,4 \\
\hline \multicolumn{2}{|c|}{ Srednia } & 88,93 & 7,67 & 3,14 \\
\hline \multicolumn{5}{|c|}{ Ostatnie dziesięć miejsc $w$ rankingu } \\
\hline 1 & Chrysler Voyager & 62,6 & 20,3 & 17,1 \\
\hline 2 & Peugeot 806 & 62,9 & 18,9 & 18,3 \\
\hline 3 & Mini & 67,3 & 22,4 & 10,3 \\
\hline 4 & VW Caravelle & 69,5 & 20,2 & 10,3 \\
\hline 5 & VW Multivan & 69,5 & 20,2 & 10,3 \\
\hline 6 & Fiat Bravo & 69,5 & 20,5 & 10,0 \\
\hline 7 & Fiat Brava & 69,5 & 20,5 & 10,0 \\
\hline 8 & Alfa Romeo 145 & 69,7 & 18,7 & 11,4 \\
\hline 9 & Alfa Romeo 146 & 69,7 & 18,7 & 11,4 \\
\hline 10 & Range Rover & 70,1 & 23,4 & 6,5 \\
\hline \multicolumn{2}{|c|}{ Średnia } & 68,03 & 20,38 & 11,56 \\
\hline
\end{tabular}

\section{Badania prowadzone przez ADAC}

Kolejną analizowaną organizacją jest niemieckie ADAC (niem. Allgemeine Deutsche Automobil Club). Organizacja zrzesza ok. 15 milionów członków. Jej głównym zadaniem jest pomoc w przypadku wystąpienia awarii pojazdu na drodze. Świadczy ona usługi w zakresie pomocy drogowej. Przy każdej interwencji sporządzany jest raport i to właśnie na ich podstawie publikowany jest corocznie raport uszkadzalności pojazdów samochodowych. Raporty te publikowane są w postaci tabel, w których podaje się liczbę ujawnionych uszkodzeń wśród 1000 egzemplarzy danego modelu pojazdu. W porównaniu do raportów TÜV i DEKRA, ADAC grupuje badane pojazdy wg odpowiednich klas. Mamy tutaj: samochody 
małe, samochody klasy niższej średniej, samochody klasy wyższej średniej, samochody klasy wyższej i luksusowej oraz samochody typu VAN.

Poniżej w tablicy 3 podano raport dla wybranej grupy pojazdów dla pierwszych dziesięciu miejsc publikowane w 2003 r. Pełen raport można znaleźć w [3].

Tablica 3

Raport uszkadzalności ADACz 2003 r. samochody klasy niższej średniej [1,3]

\begin{tabular}{|c|l|c|c|}
\hline $\begin{array}{c}\text { Miejsce } \\
\text { w raporcie }\end{array}$ & \multicolumn{1}{|c|}{ Marka/Model } & $\begin{array}{c}\text { Ilość uszkodzeń } \\
\text { na 1000 pojazdów }\end{array}$ & $\begin{array}{c}\text { Uszkodzenia } \\
{[\%]}\end{array}$ \\
\hline 1 & Toyota Starlet & 6,8 & 0,68 \\
\hline 2 & VW Polo & 13,5 & 1,35 \\
\hline 3 & Ford Fiesta & 15,3 & 1,53 \\
\hline 4 & Peugeot 106 & 15,4 & 1,54 \\
\hline 5 & Mitsubishi Colt/Ford Ka & 15,8 & 1,58 \\
\hline 6 & Citroën Saxo & 18,2 & 1,82 \\
\hline 7 & Opel Corsa & 18,4 & 1,84 \\
\hline 8 & Suzuki Swift & 20,1 & 2,01 \\
\hline 9 & Seat Cordoba & 22,0 & 2,2 \\
\hline 10 & Seat Ibiza & 22,8 & 2,28 \\
\hline 11 & Nissan Micra & 23,3 & 2,33 \\
\hline 12 & Renault Twingo & 30,5 & 3,05 \\
\hline 13 & Fiat Cinquecento & 31,6 & 3,16 \\
\hline 14 & Renault Clio & 31,9 & 3,19 \\
\hline 15 & Skoda Felicia & 32,2 & 3,22 \\
\hline 16 & Fiat Punto & 36,1 & 3,61 \\
\hline & \multicolumn{2}{|c|}{} \\
\hline
\end{tabular}

\section{Analiza wyników badań uszkadzalności prowadzonych przez wybrane organizacje}

Wyniki badań uszkadzalności pojazdów samochodowych prowadzone przez trzy organizację niemieckie wykazują pewne różnice. Sama procedura badań jest nieco odmienna. Szczególnie różnice można wykazać między procedurą zbierania wyników przez TÜV i DEKRA oraz ADAC. Ta ostatnia organizacja zbiera dane bezpośrednio $\mathrm{z}$ interwencji pomocy drogowej, a więc $\mathrm{w}$ momencie zaistnienia uszkodzenia. Jednak można wykazać pewne podobieństwa: badania są prowadzone na tym samym obszarze (Niemcy), TÜV i DEKRA przeprowadzają badania w warunkach stacji kontroli pojazdów, itd. Przedstawione w powyższych tablicach częściowe wyniki badań wybranych organizacji, które w całości można znaleźć między innymi w [1,3,4], opublikowane zostały w okresie dwóch lat. Wyniki TÜV i ADAC pochodzą z 2003 r. a DEKRA z 2002 r. Jest to okres zaledwie jednego roku i różnice $\mathrm{w}$ wynikach badań będą nieznaczne. Najważniejszym jest jednak fakt wykazania pewnych tendencji $\mathrm{w}$ rankingach publikowanych przez te organizacje. 
Analysis of the results of vehicles damages

Analiza wyników badań uszkadzalności pojazdów samochodowych

Celem przeprowadzenia porównania wyników badań wybrano trzy pojazdy, których wyniki uszkadzalności można znaleźć we wszystkich trzech raportach. Wybrano pojazdy: Fiat Bravo/Brava, VW Golf oraz Toyota Corolla. Są to jedne z najpopularniejszych modeli pojazdów, jakie można było spotkać na drogach europejskich w okresie przeprowadzania badań. Na poniższym rysunku zestawiono w formie wykresu wyniki ich badań.

Różnice pokazane na powyższym rysunku są znaczne. Szczególnie aspekt ten uwidacznia się dla pojazdów marki Fiat i Toyota. Dla Fiata różnica miedzy badaniami organizacji DEKRA i ADAC sięga prawie $27 \%$. Różnica dla pojazdu marki Toyota między DEKRA a ADAC sięga prawie $22 \%$. Można jednak w badaniach TÜV i ADAC zauważyć pewne podobieństwa. Samochód marki Toyota Corolla wykazał najmniej uszkodzeń a samochód marki Fiat Bravo/Brava wykazał najwięcej uszkodzeń. Inną tendencję zauważyć można w wynikach organizacji DEKRA. W tym przypadku najmniej uszkodzeń wykazał samochodów marki Volkswagen Golf, najwięcej - tak samo jak w poprzednich organizacjach samochód marki Fiat Bravo/Brava.

Przeprowadzona analiza wyników badań uszkadzalności pojazdów samochodowych wykazuje potrzebę ujednolicenia metodologii przeprowadzania badań i ujednorodnienia sposobów przeprowadzania testów i metod uzyskiwania wyników.

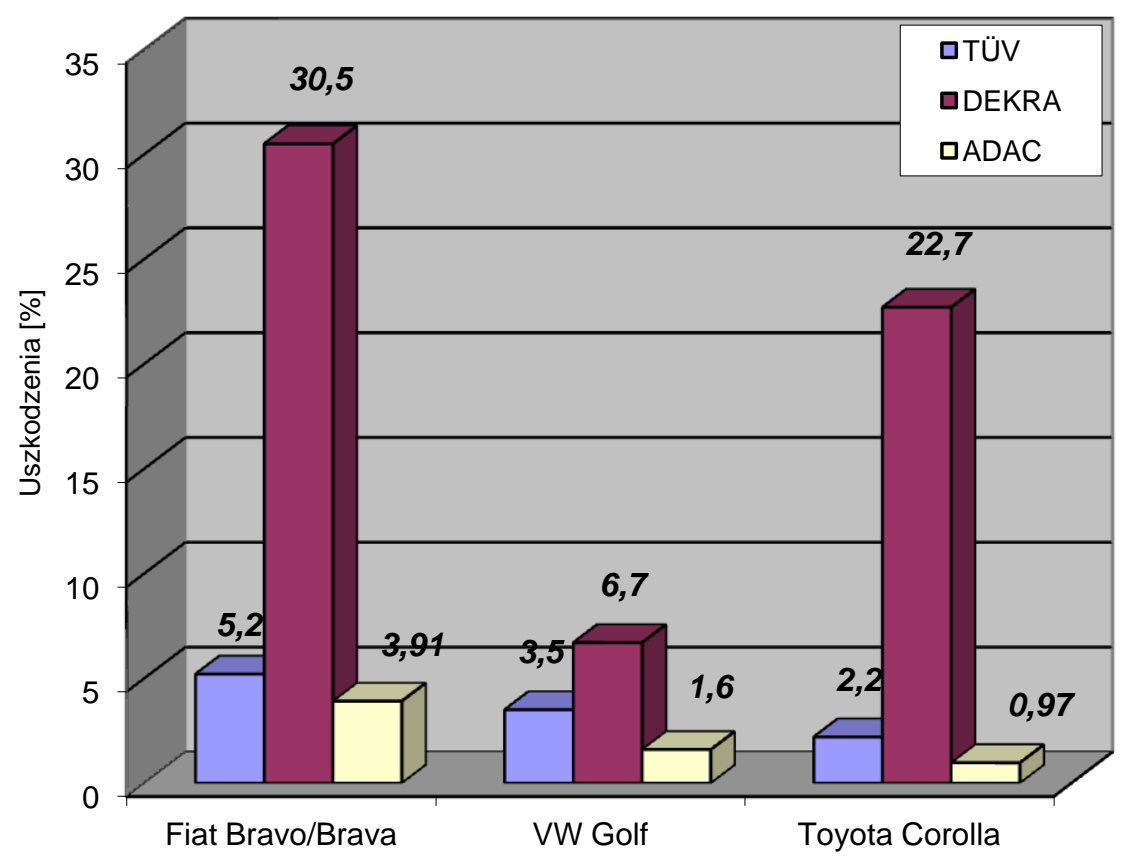

Rys. 1 Porównanie wyników badań wybranych modeli pojazdów [1] 
Celowym wydaje się stworzenie jednej metody, która bazowałaby na ogromnym doświadczeniu wyżej wymienionych organizacji. Wyniki uzyskane za pomocą takiej metody mogłyby posłużyć jako podstawę do rozszerzenia badań i analiz w zakresie uszkadzalności pojazdów samochodowych.

\section{Bibliografia}

[1] Feliczak G.: Metoda oceny stosowania układów bezpieczeństwa w pojazdach samochodowych. Praca doktorska, Raport serii PRE- 10/05, PWr, Wrocław 2006.

[2] Ważyńska - Fiok K., Jaźwiński J.: Niezawodność systemów technicznych, PWN, Warszawa 1990.

[3] Auto Świat - Katalog: Samochody Używane Nr 2/2003 (24).

[4] www.uzywane.mojeauto.pl/raport.

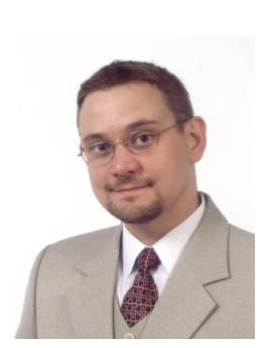

Dr inż. Grzegorz Feliczak w roku 2000 ukończyt studia na Politechnice Wroctawskiej na Wydziale Mechanicznym, Kierunek: Mechanika i Budowa Maszyn, Indywidualny Tok Studiów, broniac dwie prace magisterskie w zakresie konstrukcji mechanicznych oraz technologii mechanicznych. Następnie podjat studia doktorancie na tymże wydziale. W roku 2006 obronit prace $i$ uzyskat stopnień naukowy doktora nauk technicznych $w$ dyscyplinie budowa i eksploatacja maszyn, specjalność: pojazdy samochodowe. Jest autorem publikacji z zakresu techniki samochodowej. Obecnie pracuje na stanowisku docenta $w$ Państwowej Wyższej Szkole Zawodowej $w$ Lesznie. Jest promotorem oraz recenzentem wielu prac inżynierskich. 
Analysis of the results of vehicles damages

Analiza wyników badań uszkadzalności pojazdów samochodowych 